\title{
Sweeping is an Alternative Method for House Dust Collection for Pesticide Analysis
}

\author{
Sarah S. Birn ${ }^{1 *}$, Dawn M. Bielawski ${ }^{1}$, Enrique M. Ostrea Jr. ${ }^{1,2}$ and James J. Janisse
}

${ }^{1}$ Department of Pediatrics, Wayne State University School of Medicine, Detroit, MI, USA

${ }^{2}$ Institute of Child Health and Human Development, University of the Philippines National Institutes of Health, Manila, Philippines

${ }^{3}$ Department of Family Medicine and Public Health Sciences, Wayne State University, Detroit, MI, USA

\begin{abstract}
Analysis of pesticides in house dust, as an index of environmental pesticide exposure, is useful in the evaluation of pesticide effects in children. This study compares the prevalence and concentrations of pesticides (propoxur, transfluthrin, bioallethrin, cyfluthrin, and cypermethrin) in house dust collected by the HVS3 vacuum and by sweeping using the house broom. The pesticides were extracted from the dust samples by solid phase extraction and analyzed by gas chromatography/mass spectroscopy. There were significant correlations between the pesticides found in the swept and vacuumed samples (kappa $=0.28$ to 0.48 , rho $=0.31$ to 0.55 ). Significantly higher prevalence and concentration of propoxur and higher concentrations of pyrethroids were found in the swept compared to vacuum dust samples. We conclude that ongoing exposure of children to pesticides can be monitored by the analysis of house dust collected by sweeping. Sweeping offers an excellent alternative for house dust collection in areas where vacuum collection is not feasible.
\end{abstract}

Keywords: House dust collection; Pesticides; GC/MS; Sweeping; Vacuum

\section{Introduction}

The analysis of house dust for pesticides has been well studied [14], but only a few of these studies have been conducted in developing countries. The analysis of house dust for pesticides is useful for the detection of children's exposure to these toxic compounds since children are in close contact with dust through floor interaction or ingestion of pesticides by hand-to-mouth activity $[5,6]$.

There are many ways to collect house dust for pesticide analysis. Surface wipe tests [7-11] or vacuum collections [2,12-16] are the most frequently used methods. Other methods of dust collection have been tried Wickens et al. [12]. Compared a modified hand held vacuum cleaner (which contained a wire mesh pre-filter and a $25 \mu \mathrm{m}$ pore nylon bag) with an ALK collection device and found a change in the amount of dust collected [9]. Compared two different kinds of wipe collection, "ghost wipe" and "lead wipe" and found that the "lead wipe" collected about twice as much as the "ghost wipe" [17]. Compared lead levels by using a vacuum-based in-line filter device and wipe sampling and found the two collection methods to be correlated. The High Volume Surface Sampler (HVS3), which is considered the standard method for dust collection by the American Society for Testing and Materials [18] was compared to the household vacuum cleaner and the results showed that the household vacuum is a reasonable alternative to the HVS3 [14].

In developing countries, electricity may not always be available for vacuum collection of dust. We therefore compared the efficiency of pesticide detection in dust collected by the standard HVS3 and by broom sweeping. For this study, we analyzed in house dust for two groups of pesticides that are commonly used: propoxur and a group of pyrethroids (transfluthrin, bioallehtrin, cyfluthrin and cypermethrin). Propoxur is a carbamate whose primary mechanism of action is the inhibition of acetylcholinesterase across the synaptic gap [19]. Exposure to propoxur is through oral or dermal contact [20]. Propoxur has a high affinity for water, which makes reducing exposure easy [21]. Pyrethroids are derivatives from a mixture of compounds called pyrethrum, which are mainly found in the chrysanthemum plant
[22]. Pyrethroids break down when exposed to sunlight [22]. These compounds avidly bind to complex surfaces such as dust or dirt, and are relatively hydrophobic [22]. These are primarily airborne pesticides, so most exposure occurs by inhalation. Both propoxur and pyrethroids tend to settle into the dust after their release into air [16].

Our objective in the study was to compare pesticide prevalence and concentrations in dust samples collected by sweeping and by the HVS3 vacuum collector. Our hypothesis was that there would be no significant difference in the prevalence and concentration of pesticides (propoxur and pyrethroids) between the two methods of dust collection and that sweeping is a reasonable alternative to dust collection compared to the HVS3 vacuum.

\section{Methods}

\section{Sample population}

The study population is part of an ongoing study in Bulacan, Philippines of prenatal and postnatal exposure among children to pesticides and effects on their neurodevelopment. The ages of the children were between 4.0 and 4.5 years of age. Preliminary survey of the area showed that propoxur and transfluthrin, bioallethrin, cyfluthrin, and cypermethrin were commonly used in the house and farm [23]. There was a high reported use of household spray (43.1\%) and mosquito coil (54.9\%) pesticides at home due to the high prevalence of cockroaches, mosquitoes, and other pests within the homes [24].

*Corresponding author: Sarah S. Birn, Department of Pediatrics, Wayne State University School of Medicine, Detroit, MI, USA, Tel: (313)577-4940; E-mail: sbirn@med.wayne.edu

Received July 12, 2012; Accepted September 05, 2012; Published September 10, 2012

Citation: Birn SS, Bielawski DM, Ostrea Jr. EM, Janisse JJ (2012) Sweeping is an Alternative Method for House Dust Collection for Pesticide Analysis. J Bioanal Biomed 4: 074-078. doi:10.4172/1948-593X.1000066

Copyright: (c) 2012 Birn SS, et al. This is an open-access article distributed under the terms of the Creative Commons Attribution License, which permits unrestricted use, distribution, and reproduction in any medium, provided the original author and source are credited. 


\section{Sample collection}

House dust was collected by 2 methods: sweeping with a broom of the house (swept dust samples) and by vacuum using the HVS3 vacuum collector (vacuumed dust samples). Most of the homes were small and collection of dust samples by vacuum and sweeping would not have produced enough samples per collection method if done simultaneously. Thus, the dust sampling was done in the home, 1 week apart, starting with vacuum and then followed by sweeping. The HVS3 was thoroughly cleaned and dried between sample collections. All dust samples were placed in a plastic bag, sealed, labeled, and stored at $-20^{\circ} \mathrm{C}$. This study has been approved by the Institutional Review Boards of both Wayne State University and the University of the Philippines.

\section{Materials}

Standard parent pesticide mixture (Pestmix 11, $400 \mu \mathrm{g} \mathrm{mL} \mathrm{g}^{-1}$ ) and the internal standard (1,4-dichlorobenzene (1,4-DCB), $4000 \mu \mathrm{g} \mathrm{mL}$ $\left.{ }^{1}\right)$ were purchased from Cerilliant (Austin, TX). Pestmix 11 contains lindane, propoxur, cyfluthrin, chlorpyrfos, cypermethrin, diazinon, malathian, pynamin forte, p,p'-DDT, pretilachlar, and transfluthrin. Unbonded silica solid phase extraction columns (SPE) (1000 mg, 6 $\mathrm{mL}$ ) were purchased from United Chemical Technologies (Bristol, PA). Hexane, dichloromethane, diethyl ether, ethyl acetate, and acetone were purchased from Fisher Scientific. Nitrogen (99.999\%) was purchased from Praxair (Warren, MI).

\section{Sample preparation}

All dust samples were sieved using a stainless steel sieve with particle collection size of $150 \mu \mathrm{m}$ (Fisher Scientific) [14]. The samples were sieved in a Retsch AS 200 sieve shaker (Haan, Germany) with the amplitude set at $30 \mathrm{~Hz}$ for 4 minutes. Each sample was then weighed and placed into a test tube. The sample weights ranged between 50-100 mg. Since many of these samples included dirt or sand, sand was used as the matrix for the negative and positive controls.

\section{Preparation of standards}

Pestmix 11 was diluted in hexane to concentrations ranging from $3 \mathrm{ng} \mathrm{mL}^{-1}$ to $6,250 \mathrm{ng} \mathrm{mL}^{-1}$ to create the spiking solutions for the calibration curves. The positive control concentration was $1,560 \mathrm{ng}$ $\mathrm{mL}^{-1}$. The internal standard was diluted in hexane to a concentration of $16,000 \mathrm{ng} \mathrm{mL}^{-1}$.

\section{Pesticide extraction and clean-up}

The pesticide extraction and clean-up protocols are modifications of the procedure published by Colt et al. [14]. Three positive controls (sand spiked with 1,560 ng/mL Pestmix 11) and one negative control were used. The pesticides were extracted using $6 \mathrm{~mL}$ of a 1:1 hexane: acetone solution. The samples were sonicated for $10 \mathrm{~min}$ and then centrifuged at 4,000 $\mathrm{rpm}$ for $15 \mathrm{~min}$. Five $\mathrm{mL}$ of the supernate was transferred to a clean test tube, dried to completion under nitrogen and reconstituted in $1 \mathrm{~mL}$ of hexane. The SPE columns were conditioned as follows: $6 \mathrm{~mL} \mathrm{20 \%}$ acetone in ethyl acetate, $6 \mathrm{~mL}$ dichloromethane, 6 $\mathrm{mL} \mathrm{15 \%}$ diethyl ether in hexane, and $6 \mathrm{~mL}$ hexane. The samples were then added to the conditioned SPE columns. The pesticides were eluted sequentially with $1.5 \mathrm{~mL}$ hexane, $6 \mathrm{~mL} \mathrm{15 \%}$ diethyl ether in hexane, $3 \mathrm{~mL}$ dichloromethane, and $6 \mathrm{~mL} \mathrm{20 \%}$ acetone in ethyl acetate. The combined eluates were dried to approximately $1 \mathrm{~mL}$ under nitrogen, transferred to high recovery vials, and then dried down to completion under nitrogen. The sample was finally reconstituted in $100 \mu \mathrm{l}$ of hexane and $4 \mu \mathrm{l}$ of the diluted internal standard (1,4-DCB, 16,000 ng $\mathrm{mL}^{-1}$ ) was added for a final concentration of $615.4 \mathrm{ng} \mathrm{mL}^{-1}$.

\section{Calibration curves}

Calibration curves for propoxur, transfluthrin, bioallethrin, cyfluthrin, and cypermethrin were constructed by spiking sand with varying concentrations of the parent pesticide standard mix (Pestmix 11). These concentrations ranged from $3 \mathrm{ng} \mathrm{mL}^{-1}$ to $6,250 \mathrm{ng} \mathrm{mL} L^{-1}$. Empirical limits of detection were determined as recommended $[25,26]$.

\section{Gas Chromatography/Mass Spectrometry (GC/MS) analytical conditions}

Pesticide analysis was done using an HP 6890 GC and a HP 5973 MS. An Agilent Technologies 7683 series autosampler was used for sample injection. The GC column was a $30 \mathrm{~m} \mathrm{J \& W} \mathrm{DB-5MS} \mathrm{capillary}$ column ([5\%-phenyl]-methylpolysiloxane, $0.25 \mathrm{~mm} \mathrm{ID,} 1 \mu \mathrm{m}$ film thickness) obtained from Agilent Technologies. An HP Chemstation version B.01.00 was used to generate analytical data. The GC/MS conditions are described in a previous publication [24]. One $\mu \mathrm{l}$ of the sample was injected into the GC front inlet $\left(250^{\circ} \mathrm{C}\right)$ using the autosampler in splitless mode. The initial oven temperature was set at $70^{\circ} \mathrm{C}$, and increased at a rate of $10^{\circ} \mathrm{C} \mathrm{min}^{-1}$ until the final temperature of $300^{\circ} \mathrm{C}$ was reached and maintained for $10 \mathrm{~min}$. Data was collected in SIM mode.

\section{Quantitation of samples}

The Data Analysis computer program (HP Chemstation version B.01.00) was used for quantifying the acquired data. The concentration of pesticides present in each sample was determined using the calibration curves. The identity of a pesticide in the sample was established if the following criteria were satisfied: 1) the peak was +/- 0.03 min from the retention time as determined from positive control standards and 2) the target and qualifier ion(s) were within the established ratio (+/- 30\%). Table 1 lists the target and qualifier ion(s) along with the retention time $\left(t_{R}\right)$ for each parent pesticide.

\section{Statistics}

Statistical analysis was performed using SPSS version 19. SPSS Data Entry 4.0 was used to set up the databases and double entry of the data was performed in order to reduce the potential for data entry errors. The median and interquartile ranges were used to describe the concentration of positive samples for each pesticide. The McNemar and Wilcoxon tests were used to compare the pesticide prevalence and concentration, respectively, in swept and vacuumed dust. Kappa and Spearman Rho were used to assess the agreement of the swept and

\begin{tabular}{|c|c|c|c|c|}
\hline Compounds & $\begin{array}{c}\text { Target lon } \\
m / z\end{array}$ & $\begin{array}{c}\text { Qualifier lon(s) } \\
m / z\end{array}$ & $t_{R}(m i n)$ & $r^{2}$ \\
\hline 1,4-dichlorobenzene (IS) & 152 & 150,115 & 8.89 & N/A \\
\hline Propoxur & 110 & 152 & 17.49 & 0.987 \\
\hline Transfluthrin & 163 & 91,335 & 20.71 & 0.988 \\
\hline Bioallethrin & 123 & 79,136 & 22.53 & 0.994 \\
\hline Cyfluthrin & 206 & 226 & 31.84 & 0.999 \\
\hline Cypermethrin & 181 & 209 & 32.99 & 1.000 \\
\hline
\end{tabular}

Table 1: Target and qualifier ion(s), retention times $\left(t_{R}\right)$, and coefficients of determination $\left(r^{2}\right)$ for parent pesticides. 
vacuumed samples for prevalence and concentration. To determine if type of flooring (non-dirt versus dirt) impacted prevalence and concentration of pesticides values were compared using the Fisher's Exact Test and Mann-Whitney Test. Statistics presented are based on the 388 cases with data on both swept and vacuumed methods.

\section{Results}

\section{Analytical method}

The pesticides are listed in Table 1 with their target and qualifier ion $(\mathrm{s})$ and their retention times $\left(\mathrm{t}_{\mathrm{R}}\right)$. The coefficients of determination $\left(\mathrm{r}^{2}\right)$ in Table 1 range from 0.987 to 1.000 . These were determined from calibration curves generated using a standard mix of pesticides spiked in sand. Analysis of the dust samples produced no interfering peaks was determined by running a negative control in each batch.

\section{Method validation}

The mean (SD) pesticide recovery (\%), coefficients of variation, and empirical LODs for the dust samples $(\mathrm{N}=20)$ are shown in Table 2. The mean (SD) recoveries range from $90.75 \%( \pm 11.53)$ for cyfluthrin to $105.56 \%( \pm 8.41)$ for transfluthrin. The mean (SD) for the CV ranged from $5.52 \%( \pm 3.93)$ for cypermethrin to $7.42 \%( \pm 4.77)$ for cyfluthrin. The empirical LODs are the same as for swept dust. All recoveries and coefficients of variation are based on spiked sand samples with a concentration of $1,950 \mathrm{ng} \mathrm{g}^{-1}$.

\section{Analysis of pesticides in house dust}

A total of 575 swept and 429 vacuum dust samples were collected from the different homes. There were more swept compared to vacuum samples because collection of swept dust was started ahead while waiting for the HVS3 vacuum equipment to arrive. When the HVS3 became available, paired swept and vacuum samples were collected per home. However, for this report, only paired swept and vacuum samples were analyzed ( $\mathrm{N}=388$ pairs). The type of house flooring in the 388 paired samples varied in the different homes: $73.7 \%$ had cement floor, $2.6 \%$ wood floor, $11.1 \%$ gravel/soil floor, $6.4 \%$ linoleum, $0.8 \%$ carpet floor, $5.2 \%$ tile floor and $0.3 \%$ marble floor. Propoxur, bioallethrin, transfluthrin, cyfluthrin and cypermethrin were detected in both swept and vacuumed house dust (Table 3 ). The pesticide with highest prevalence was bioallethrin $(25.8 \%)$, while the pesticide with lowest prevalence was cyfluthrin (2.6\%). There was significant agreement between swept and vacuumed samples for all pesticides (kappa $=0.28$ to $0.48, \mathrm{p}<0.001$ for all). However, the rate of detection of propoxur

\begin{tabular}{|c|c|c|c|c|}
\hline Compounds & $\begin{array}{c}\text { Target lon } \\
\mathrm{m} / \mathbf{z}\end{array}$ & $\begin{array}{c}\text { Qualifier lon(s) } \\
\mathrm{m} / \mathrm{z}\end{array}$ & $\mathrm{t}_{\mathrm{R}}(\mathrm{min})$ & $\mathrm{r}^{2}$ \\
\hline 1,4-dichlorobenzene (IS) & 152 & 150,115 & 8.89 & $\mathrm{~N} / \mathrm{A}$ \\
\hline Propoxur & 110 & 152 & 17.49 & 0.987 \\
\hline Transfluthrin & 163 & 91,335 & 20.71 & 0.988 \\
\hline Bioallethrin & 123 & 79,136 & 22.53 & 0.994 \\
\hline Cyfluthrin & 206 & 226 & 31.84 & 0.999 \\
\hline Cypermethrin & 181 & 209 & 32.99 & 1.000 \\
\hline
\end{tabular}

${ }^{1}$ Percent coefficient of variation is calculated as the standard deviation/mean recovery $x 100$

Table 2: Mean (SD) of pesticide recovery (\%), coefficients of variation (\%CV), for the analysis of parent pesticides in dust $(\mathrm{N}=20)$ spiked with $1,950 \mathrm{ng} / \mathrm{g}$ pesticides and the lowest empirical limits of detection (LODs) based on calibration curves.

\begin{tabular}{|c|c|c|c|c|}
\hline Pesticides & $\begin{array}{c}\text { Swept house } \\
\text { dust }\end{array}$ & $\begin{array}{c}\text { Vacuumed } \\
\text { house } \\
\text { dust }\end{array}$ & $\begin{array}{c}\text { Comparing } \\
\text { Prevalence } \\
\text { p value }^{1}\end{array}$ & $\begin{array}{c}\text { Agreement of } \\
\text { Prevalence }^{2}\end{array}$ \\
\hline Propoxur & 9.8 & 4.6 & 0.002 & 0.28 \\
\hline Transfluthrin & 4.4 & 3.1 & $0.332^{3}$ & 0.39 \\
\hline Bioallethrin & 25.0 & 25.8 & 0.740 & 0.45 \\
\hline Cyfluthrin & 4.1 & 2.6 & $0.180^{3}$ & 0.44 \\
\hline Cypermethrin & 6.2 & 4.9 & $0.383^{3}$ & 0.48 \\
\hline
\end{tabular}

${ }^{1}$ McNemar test

${ }^{2}$ Kappa ( $p<0.001$ for all)

${ }^{3}$ Exact test using binomial distribution.

Table 3: Prevalence (\%) of pesticides in swept house dust and vacuumed house dust $(\mathrm{N}=388)$.

\begin{tabular}{|c|c|c|c|c|}
\hline Pesticides & $\begin{array}{c}\text { Swept house } \\
\text { dust }\end{array}$ & $\begin{array}{c}\text { Vacuumed } \\
\text { house dust }\end{array}$ & $\begin{array}{c}\text { Comparing } \\
\text { Concentration } \\
\text { p value }^{1}\end{array}$ & $\begin{array}{c}\text { Agreement of } \\
\text { Concentration }\end{array}$ \\
\hline Propoxur & $\begin{array}{c}48.87 \\
(19.9-118.4)\end{array}$ & $\begin{array}{c}27.11 \\
(13.6-153.4)\end{array}$ & $<0.001$ & 0.31 \\
\hline Transfluthrin & $\begin{array}{c}31.56 \\
(13.8-59.0)\end{array}$ & $\begin{array}{c}21.91 \\
(16.9-32.5)\end{array}$ & 0.048 & 0.40 \\
\hline Bioallethrin & $\begin{array}{c}208.36 \\
(94.9-447.1)\end{array}$ & $\begin{array}{c}174.38 \\
(50.7-404.6)\end{array}$ & 0.016 & 0.55 \\
\hline Cyfluthrin & $\begin{array}{c}740.00 \\
(155.5-1174.1)\end{array}$ & $\begin{array}{c}399.45 \\
(162.1-1506.3)\end{array}$ & 0.079 & 0.47 \\
\hline Cypermethrin & $\begin{array}{c}467.25 \\
(214.4-884.9)\end{array}$ & $\begin{array}{c}837.44 \\
(461.4-5480.8)\end{array}$ & 0.654 & 0.50 \\
\hline
\end{tabular}

${ }^{1}$ Wilcoxon Signed Ranks Test based on samples with both swept and vacuumed dust $(\mathrm{N}=388)$

${ }^{2}$ Spearman Rho based on samples with both swept and vacuumed dust $(\mathrm{N}=388$, $p<0.001$ for all)

Table 4: Median and interquartile range of pesticide concentrations $(\mathrm{ng} / \mathrm{g})$ in swept house dust and vacuumed house dust for samples with positive cases.

was significantly higher in swept compared to vacuumed dust samples (9.8\% versus $4.6 \%, \mathrm{p}=0.002)$.

The concentrations of pesticides detected in swept and vacuumed dust are shown in Table 4 . Since the prevalence of each pesticide was $<50 \%$, presenting the median concentration for all samples would provide no information. For this reason the median concentration and interquartile range is presented using only cases with positive prevalence. Assessment of agreement and comparisons between concentrations were based on all cases both positive and negative. There was significant agreement between swept and vacuumed concentrations for all pesticides ( $r h o=0.31$ to $0.55, \mathrm{p}<0.001$ for all) (Figures $1 \& 2$ ). However, the p values stated in Fig 1 and 2 are likely inflated due to the presence of a high proportion of non-detects by both methods. There were significantly higher concentrations of propoxur $(\mathrm{p}<0.001)$, transfluthrin $(\mathrm{p}=0.048)$, and bioallethrin $(\mathrm{p}=0.016)$ in swept compared to vacuumed dust.

The type of flooring in the home was not related to the prevalence or concentration of pesticides (Table 5).

\section{Discussion}

The monitoring of ongoing exposure to pesticides in very young children is essential in a study of the long term adverse effects of pesticides on children's neurodevelopment. In a cohort of 4 year old children who have been participants since birth in a longitudinal study of the adverse effects of pesticide exposure, this study shows that environmental (house dust) is a good matrix to analyze for the detection of risk to ongoing exposure to pesticides. Children are 
exposed to pesticides in house dust via three ways: (1) inhalation, (2) oral ingestion, and (3) dermal uptake. For small children, the oral and dermal routes are the most common [1]. Some characteristics of children increase their exposure to pesticides in house dust (1) Their hand to mouth behavior increases their ingestion of any toxic chemicals in dust or soil and (2) the likelihood of playing close to the ground increases their exposure to toxins in the dust, soil and carpets as well as to any toxicants that form low-lying layers in the air, such as certain pesticide vapors. Thus, exposure to house dust is a significant pathway for the children's exposure to pesticides [5,6]. Studies have also indicated that more pesticides and higher pesticide concentrations are found in household dust as compared to air, soil, and food $[4,16]$.

On the other hand, the method of dust collection can be of concern especially in developing countries where electricity may not always be available. Most publications have used a standard vacuum cleaner for dust collection $[27,28]$. We have compared the prevalence and concentrations of propoxur, cyfluthrin, transfluthrin, bioallethrin and cypermethrin in house dust collected by broom sweeping and a standard environmental vacuum collector (HVS3) which is recommended by the American Society for Testing and Materials [18] Our results showed that swept dust was as efficient and yielded comparable results in terms of positivity and concentration of pesticides as compared with the HVS3 vacuum (kappa $=0.28$ to 0.48 , rho $=0.31$ to 0.55 ). In

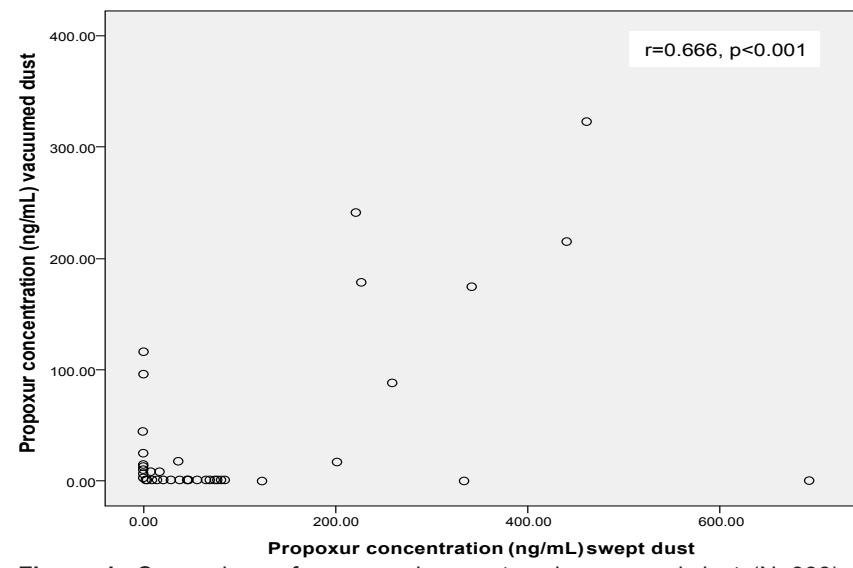

Figure 1: Comparison of propoxur in swept and vacuumed dust $(\mathrm{N}=388)$. Samples that had both swept and vacuumed results were included.

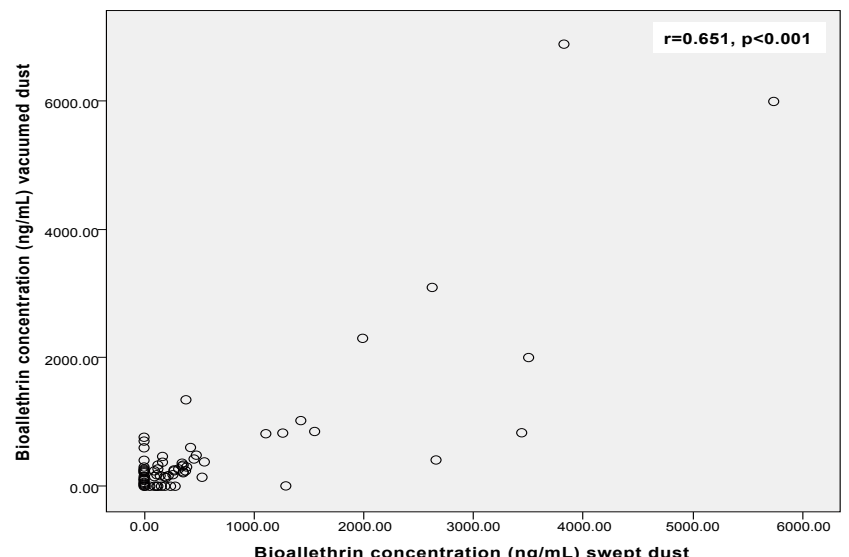

Figure 2: Comparison of bioallethrin in swept and vacuumed dust $(\mathrm{N}=388)$. Samples that had both swept and vacuumed results were included.

\begin{tabular}{|c|c|c|c|c|c|}
\hline $\begin{array}{l}\text { Method of } \\
\text { Pesticide } \\
\text { Collection }\end{array}$ & Pesticides & $\begin{array}{l}\text { Non-Dirt } \\
\text { Floor }^{1} \\
(\mathrm{~N}=345)\end{array}$ & $\begin{array}{l}\text { Dirt Floor }{ }^{1} \\
\quad(\mathrm{~N}=43)\end{array}$ & $\begin{array}{c}\text { Comparing } \\
\text { Prevalence } \\
p \text { value }\end{array}$ & $\begin{array}{c}\text { Comparing } \\
\text { Concentration } \\
\text { p value }{ }^{3}\end{array}$ \\
\hline \multicolumn{6}{|c|}{ Swept House Dust } \\
\hline & Propoxur & 9.9 & 9.3 & 1.000 & 0.808 \\
\hline & Transfluthrin & 4.1 & 7.0 & 0.418 & 0.390 \\
\hline & Bioallethrin & 24.6 & 27.9 & 0.709 & 0.718 \\
\hline & Cyfluthrin & 4.3 & 2.3 & 1.000 & 0.534 \\
\hline & Cypermethrin & 6.7 & 2.3 & 0.498 & 0.252 \\
\hline \multicolumn{6}{|c|}{ Vacuumed House Dust } \\
\hline & Propoxur & 4.9 & 2.3 & 0.706 & 0.437 \\
\hline & Transfluthrin & 3.2 & 2.3 & 1.000 & 0.749 \\
\hline & Bioallethrin & 26.4 & 20.9 & 0.579 & 0.577 \\
\hline & Cyfluthrin & 2.9 & 0.0 & 0.610 & 0.259 \\
\hline & Cypermethrin & 5.5 & 0.0 & 0.248 & 0.115 \\
\hline
\end{tabular}

$1 \%$ of positive cases is given

${ }^{2}$ Fisher's Exact Test

${ }^{3}$ Mann-Whitney Test

Table 5: Comparing prevalence (\%) and concentration of pesticides by type of flooring: Non-dirt floor includes cement, wood, linoleum, carpet, tile and marble floors. Dirt floor includes gravel/soil type of floor.

fact, there was a significantly higher prevalence of propoxur as well as higher concentrations of propoxur, transfluthrin and bioallethrin in swept compared to vacuum collected dust. The lower positive rate and concentration of some pesticides in vacuum dust could be due to the fact that the HVS3 was designed for carpeted surfaces and the floor surfaces of most homes were either cement, dirt, tile, linoleum or wood floors and sweeping is preferred method of dust collection on these surfaces. One added advantage of house dust collection by sweeping is that the HVS3 equipment is heavy and difficult to transport particularly in remote areas where rice fields have to be crossed to access the homes that do not have the benefit of paved roads [29-35].

\section{Conclusion}

The high recovery rates and concentrations of pesticides in dust collected by sweeping alone as compared to the standard HVS3 collector offers an important, effective alternative for dust collection, particularly in developing countries where homes have dirt or cement floors and electricity is limited or not available.

\section{Acknowledgments}

Funding sources: This study is supported by grants from National Institutes of Child Health and Human Development, United States National Institutes of Health (1RO1HD039428) and the United States Environmental Protection Agency (RFA 2001-STAR-H1) No. R829395e.

This study was approved by the Human Investigation Committees at Wayne State University, Detroit, Michigan and the University of the Philippines, Manila, Philippines. There is no competing financial interest.

\section{References}

1. Berger-Preiss E, Levsen K, Leng G, Idel H, Sugiri D, et al. (2002) Indoor pyrethroid exposure in homes with woollen textile floor coverings. Int $\mathrm{J}$ Hyg Environ Health 205: 459-472.

2. Colt JS (1998) Comparison of pesticides and other compounds in carpet dust samples collected from used vacuum cleaner bags and from a high-volume surface sampler. Environ Health Perspect 106: 721-724.

3. Herrera-Portugal C, Ochoa H, Franco-Sánchez G, Yáñez L, DÃaz-Barriga $F$ 
Citation: Birn SS, Bielawski DM, Ostrea Jr. EM, Janisse JJ (2012) Sweeping is an Alternative Method for House Dust Collection for Pesticide Analysis. J Bioanal Biomed 4: 074-078. doi:10.4172/1948-593X.1000066

(2005) Environmental pathways of exposure to DDT for children living in a malarious area of Chiapas, Mexico. Environ Res 99: 158-163.

4. Simcox NJ, Fenske RA, Wolz SA, Lee IC, Kalman DA (1995) Pesticides in household dust and soil: exposure pathways for children of agricultural families. Environ Health Perspect 103: 1126-1134.

5. Bradman A, Whyatt RM (2005) Characterizing exposures to nonpersistent pesticides during pregnancy and early childhood in the National Children's Study: a review of monitoring and measurement methodologies. Environ Health Perspect 113: 1092-1099.

6. Clayton AC, Pellizari ED, Whitmore RW, Quackenboss JJ, Adgate J, et al (2003) Distributions, associations, and partial aggregate exposure of pesticides and polynuclear aromatic hydrocarbons in the Minnesota children's pesticide exposure study (MNCPES). J Expo Anal Environ Epidemiol 13: 100-111.

7. Byrne SL, Shurdut BA, Saunders DG (1998) Potential chlorpyrifos exposure to residents following standard crack and crevice treatment. Environ Health Perspect 106: 725-731

8. Bradman A, Whyatt RM (2005) Characterizing exposures to nonpersistent pesticides during pregnancy and early childhood in the National Children's Study: a review of monitoring and measurement methodologies. Environ Health Perspect 113: 1092-1099.

9. Johnson DL, Hunt A, Griffith DA, Hager JM, Brooks J, et al. (2009) Geographic patterns of non-carpeted floor dust loading in Syracuse, New York (USA) homes. Environ Geochem Health 31: 353-363.

10. Krieger RI, Rosenheck LA, Schuester LL (1997) Adult and infant abamectin exposures following Avert 310 and pressurized gel crack and crevice treatment. Bull Environ Contam Toxicol 58: 681-687.

11. Ross J, Fong HR, Thongsinthusak T, Margetich S, Krieger R (1991) Measuring potential dermal transfer of surface pesticide residue generated from indoor fogger use: using the CDFA roller method interim report II. Chemosphere 22: 975-984.

12. Wickens K, Lane J, Siebers R, Ingham T, Crane J (2004) Comparison of two dust collection methods for reservoir indoor allergens and endotoxin on carpets and mattresses. Indoor Air 14: 217-222.

13. Coronado GD, Thompson B, Strong L, Griffith WC, Islas I (2004) Agricultural task and exposure to organophosphate pesticides among farmworkers. Environ Health Perspect 112: 142-147.

14. Colt JS, Gunier RB, Metayer C, Nishioka MG, Bell EM, et al. (2008) Household vacuum cleaners vs. the high-volume surface sampler for collection of carpet dust samples in epidemiologic studies of children. Environ Health 7: 6 .

15. Bradman MA, Harnly ME, Draper W, Seidel S, Teran S, et al. (1997) Pesticide exposures to children from California's Central Valley: results of a pilot study. $J$ Expo Anal Environ Epidemiol 7: 217-234.

16. Lewis RG, Fortmann RC, Camann DE (1994) Evaluation of methods for monitoring the potential exposure of small children to pesticides in the residential environment. Arch Environ Contam Toxicol 26: 37-46.

17. Farfal MR, Lees PSJ, Rohde CA, Lim BS, Bannon D, Chisolm JJ. 1994 Comparison of a wipe and a vacuum collection method for the determination of lead in residental dusts. Environ Res. 65:291-301.

18. American Society for Testing and Materials (2002) Standard practice for the collection of floor dust for chemical analysis. Standard Practice D5438-00, Philadelphia, PA: American Society for Testing and Materials.

19. http://www.who.int/whopes/quality/en/propoxur_eval_spec_WHO_ October_2005.pdf

20. Baron RL (1991) In Handbook of Pesticide Toxicology. New York (NY): Hayes WJ Jr and Laws ER Jr, Eds. Academic Press. Carbamate insecticides.

21. Wauchope RD, Buttler TM, Hornsby AG, Augustijn-Beckers PW, Burt JP (1992) The SCS/ARS/CES pesticide properties database for environmental decisionmaking. Rev Environ Contam Toxicol 123: 1-155

22. http://www.atsdr.cdc.gov/toxprofiles/tp.asp?id=787\&tid=153

23. Ostrea EM, Villanueva-Uy E, Bielawski DM, Posecion NC Jr, Corrion ML, et al.
(2006) Maternal hair--an appropriate matrix for detecting maternal exposure to pesticides during pregnancy. Environ Res 101: 312-322.

24. Colt JS, Severson RK, Lubin J, Rothman N, Camann D, et al. (2005) Organochlorines in carpet dust and Non-Hodgkin Lymphoma. Epidemiology 16: $516-525$

25. Hong S, Kim J, Lemley AT, Obendorf SK, Hedge A (2001) Analytical method development for 18 pesticides in house dust and settled residues using SEC, SPE, TMS methylation, and GC-MS. J Chromatogr Sci 39: 101-112.

26. Curl CL, Fenske RA, Kissel JC, Shirai JH, Moate TF, et al. (2002) Evaluation of take-home organophosphorus pesticide exposure among agricultural workers and their children. Environ Health Perspect 110: A787-792.

27. Babu GR, Reddy GR, Reddy AT, Rajendra W, Chetty CS (1990) Effect in vitro of propoxur on calcium dependent ATP hydrolysis and calcium uptake by the rat brain synaptosomes. Biochem Int 21: 1089-1094.

28. Corrion ML, Ostrea EM Jr, Bielawski DM, Posecion NC Jr, Seagraves JJ (2005) Detection of prenatal exposure to several classes of environmental toxicants and their metabolites by gas chromatography-mass spectrometry in maternal and umbilical cord blood. J Chromatogr B Analyt Technol Biomed Life Sci 822 221-229.

29. Bloomquist JR (1996) lon channels as targets for insecticides. Annu Rev Entomol 41: 163-190.

30. Colt JS, Lubin J, Camann D, Davis S, Cerhan J, et al. (2004) Comparison of pesticide levels in carpet dust and self-reported pest treatment practices in four US sites. J Expo Anal Environ Epidemiol 14: 74-83.

31. Farfel MR, Lees PS, Rohde CA, Lim BS, Bannon D, et al. (1994) Comparison of a wipe and a vacuum collection method for the determination of lead in residential dusts. Environ Res 65: 291-301.

32. Lewis RG, Fortune CR, Willis RD, Camann DE, Antley JT (1999) Distribution of pesticides and polycyclic aromatic hydrocarbons in house dust as a function of particle size. Environ Health Perspect 107: 721-726.

33. Narahashi T (1992) Nerve membrane $\mathrm{Na}+$ channels as targets of insecticides. Trends Pharmacol Sci 13: 236-241.

34. Narahashi T (1996) Neuronal ion channels as the target sites of insecticides Pharmacol Toxicol 79: 1-14. 